\title{
Epidemiology, morbidity and mortality from fall-related injuries in the United Arab Emirates
}

\author{
Michal Grivna', Hani O Eid ${ }^{2}$ and Fikri M Abu-Zidan²
}

\begin{abstract}
Background: Unintentional falls are a major cause of morbidity and mortality with a significant burden on victims, families, and societies. We aimed to study the mechanism, risk factors, and outcome of hospitalized patients with fall-related injuries in order to propose preventive measures.

Methods: Fall-related injured patients who were admitted to Al Ain Hospital, United Arab Emirates (UAE) for more than 24 hours or who died after arrival to the hospital, were studied over 3 years. Demography, location and time of injury, affected body regions, hospital and ICU stay, and outcome were analyzed.

Results: 882 patients were studied, $82 \%$ were males, and 22\% were less than 19 years old. Majority were from the Indian subcontinent. The most common location for fall injuries was work. Patients injured at work were older and mainly non-UAE nationals $(p<0.0001)$ when compared with those injured at home. Patients falling from height, when compared with those falling from same level, were older $(p=0.017)$, had more males $(p<0.001)$, were mainly from the Indian subcontinent $(p<0.001)$, had higher ISS $(p=0.011)$ and longer total hospital stay $(p<0.001)$.

Conclusions: Falls are a major health problem in the UAE. Falls at work can be prevented by safety education tailored to different ethnic groups, and proper legislation and regulation. Environmental modification using evidence-based architectural design may prevent falls among vulnerable risk groups.
\end{abstract}

Keywords: Falls, Elderly, Injury, Prevention, United Arab Emirates

\section{Background}

Unintentional falls are a major cause of morbidity and mortality with a significant burden on victims, families, and societies [1]. They are the second leading cause of injury-related hospitalization for all ages, accounting for about $30-40 \%$ of injury admissions [2,3]. Falls present $10-15 \%$ of all Emergency Department visits [4]. More than $60 \%$ of injury-related hospitalizations of the elderly is due to falls which cause hip fractures, traumatic brain injuries and upper limb injuries [2,3]. The cost of fallrelated injuries and their effects on the health care systems are high $[5,6]$.

United Arab Emirates (UAE) is a fast developing country with a population of more than 6 million. Falls were the second cause of trauma deaths following road traffic collisions with a death incidence rate of 7.4 per 100000 population [7]. The personal, environmental, and equipment

\footnotetext{
* Correspondence: fabuzidan@uaeu.ac.ae

${ }^{2}$ Trauma Group, Department of Surgery, College of Medicine and Health Sciences, UAE University, PO Box 17666, Al Ain, United Arab Emirates Full list of author information is available at the end of the article
}

risk factors for falls vary in different communities. It is important to conduct proper epidemiological studies if we aim to propose useful preventive measures. There is little information on falls in the Gulf area of the Middle East. We aimed to study the mechanism of injury, severity and outcome of hospitalized fall-related injuries in the $\mathrm{UAE}$ in order to give recommendations regarding their prevention.

\section{Methods}

Ethics statement

The Local Ethics Committee of Al Ain Health District Area has approved data collection for all trauma patients who were admitted to $\mathrm{Al}$ Ain Hospital or who died in the Emergency Department (UAE RECA/02/44). Data were collected prospectively on a specially designed hard copy form. All patients or their care givers signed a consent form for permitting the use of anonymous data for research or audit. 


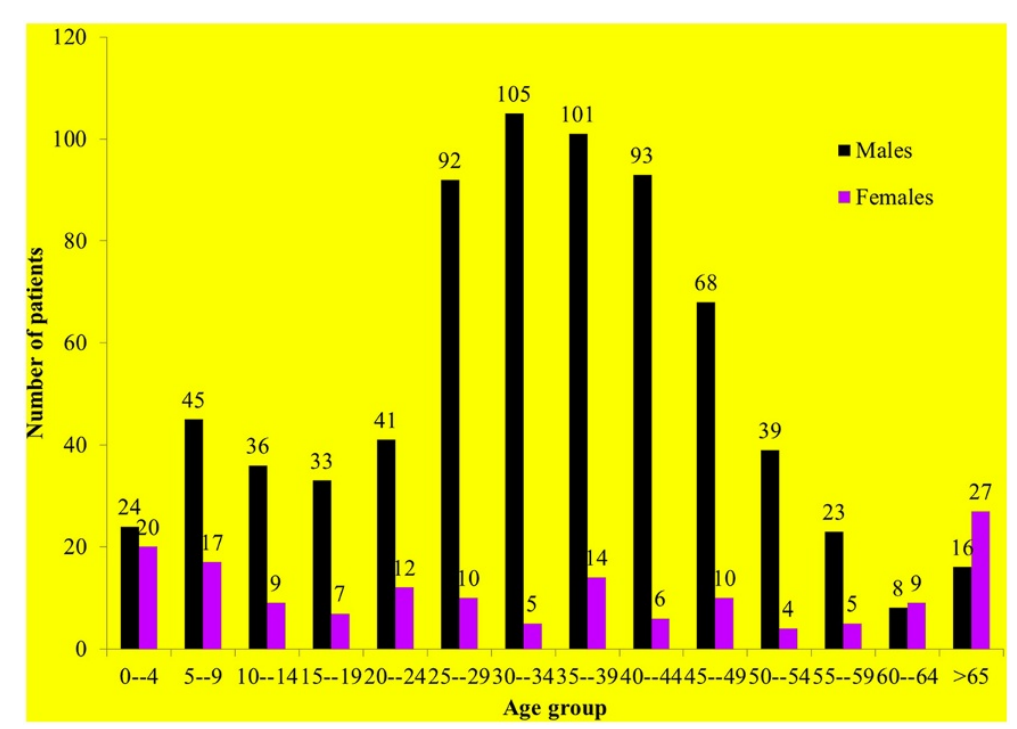

Figure 1 Age distribution of fall patients by gender ( $n=727$ males, $n=155$ females), males = black bars; females $=$ purple bars.

We studied all fall-related injured patients who were admitted to Al Ain Hospital for more than 24 hours, or who died after arrival to the hospital during the period of March 2003 - March 2006. Al Ain hospital is a major hospital of Al Ain City, which has a population of about half a million [8]. Data were retrieved from Al Ain Hospital Trauma Registry, which were prospectively collected by a full time Research Fellow. Variables studied included age, gender, nationality, location of fall, type of fall (from height or same level), time and date of the fall, injured anatomical body regions, intensive care unit (ICU) admission, duration of hospital stay, and mortality.

Severity of injury of the affected body region was assessed by the Abbreviated Injury Scale (AIS) and by the Injury Severity Score (ISS) [9,10]. The ISS was calculated manually using the Abbreviated Injury Scale Handbook [11]. The AIS has a value of $1-5$ while ISS has a value of $1-75$.

\section{Statistical analysis}

Data were analyzed using the Statistical Package for the Social Sciences (IBM-SPSS version 20, Chicago, Il). The Mann-Whitney U-test or Fisher's exact test were used to compare two independent groups of continuous, ordinal, or categorical data. The Kruskal-Wallis non parametric test was used to compare continuous or ordinal data for more than two independent groups. Probabilities of less than 0.05 were accepted as statistically significant.

We estimated the incidence rates using 2005 UAE census data with an assumption that $\mathrm{Al}$ Ain City population structure is similar to that of the whole UAE [8].

\section{Results}

There were 882 patients, 727 males (82\%) (male:female ratio was 4.7:1). Mean (SD) age was 32.8 (17.4) years, majority were adults in the productive years of 20-54 years old $(68 \% ; n=600)$. Twenty two percent $(n=187)$ were children and youth $<19$ years (Figure 1). Majority of patients were from the Indian subcontinent $(52 \% ; \mathrm{n}=454)$, followed by Arabs $(25 \% ; \mathrm{n}=217)$, UAE nationals $(15 \%$; $n=129)$, other Asians $(5 \% ; n=47)$, and others $3 \%(n=27)$.

Work was the most common location for fall injury (51\%; $\mathrm{n}=451)$, followed by home $(37 \% ; \mathrm{n}=324)$ and others $(12 \% ; n=107)$. Patients injured at work were significantly older than those injured at home or other locations $(\mathrm{p}<0.0001)$ (Table 1$)$. Females and UAE nationals were significantly more injured at home compared with males and non-UAE nationals $(\mathrm{p}<0.0001)$ (Table 1). Other locations included road, off-road, public buildings, public area, hotels/clubs and others (12\%; $\mathrm{n}=107$ ).

Table 1 Location of falls by age, gender and nationality, Al Ain Hospital, 2003-2006 ( $n=882$ )

\begin{tabular}{llllll}
\hline Variable & & $\begin{array}{l}\text { Home } \\
\mathbf{n = 3 2 4}\end{array}$ & $\begin{array}{l}\text { Work } \\
\mathbf{n = 4 5 1}\end{array}$ & $\begin{array}{l}\text { Other } \\
\mathbf{n = 1 0 7}\end{array}$ & p-value* \\
\hline Age & & $26(1-100)$ & $35(4-76)$ & $20.0(3-75)$ & $<0.0001$ \\
Gender & Male & $186(57.4 \%)$ & $448(99.3 \%)$ & $93(86.9 \%)$ & $<0.0001$ \\
& Female & $138(42.6 \%)$ & $3(0.7 \%)$ & $14(13.1 \%)$ & \\
\multirow{2}{*}{ Nationality } & UAE & $94(29.3 \%)$ & $7(1.6 \%)$ & $28(26.4 \%)$ & $<0.0001$ \\
& Non-UAE & $227(70.7 \%)$ & $440(98.4 \%)$ & $78(73.6 \%)$ & \\
\hline
\end{tabular}

${ }^{*} \mathrm{p}=$ Kruskall Wallis test or Fisher's Exact test as appropriate. Data are presented as median (range) and number (\%) as appropriate. Data on nationality were missing in three patients falling at home, 4 patients falling at work, and one patient falling elsewhere. 
Table 2 Demographic and severity variables by type of falls, Al Ain Hospital, 2003-2006 ( $\mathbf{n}=\mathbf{8 8 2}$ )

\begin{tabular}{llll}
\hline Variable & Fall from same level $(\mathbf{n}=\mathbf{3 8 1})$ & Fall from height $(\mathbf{n}=\mathbf{5 0 1})$ & $\mathbf{p}$-value* \\
\hline Age (years) & $31(1-95)$ & $34(2-100)$ & 0.017 \\
Gender (male) & $273(71.7 \%)$ & $454(90.6 \%)$ & $<0.001$ \\
Nationality (Indian subcontinent) & $141(37.1 \%)^{\mathrm{a}}$ & $313(63.4 \%)^{\mathrm{a}}$ & $<0.001$ \\
ICU admission & $4(1 \%)$ & $26(5.2 \%)$ & 0.001 \\
Length of hospital stay (days) & $5(1-85)$ & $6(1-150)$ & $<0.001$ \\
ISS & $4(1-25)$ & $4(1-34)$ & 0.011 \\
\hline
\end{tabular}

${ }^{*} p=$ Fisher's Exact test or Mann Whitney test as appropriate; Data are presented as number (\%) or median (range) as appropriate. $a=$ NB. Data on nationality were missing in one patient falling from same level and seven patients falling from height.

There were more patients with falls from height (57\%; $\mathrm{n}=501)$ than from same level $(43 \% ; \mathrm{n}=381)$ (Table 2$)$. Patients falling from height, when compared with those falling from same level, were older $(p=0.017)$, had more males $(p<0.001)$, were mainly from the Indian subcontinent $(p<0.001)$, had higher ISS $(p=0.011)$, were more admitted to the ICU $(\mathrm{p}=0.001)$, and had longer total hospital stay $(\mathrm{p}<0.001)$ (Table 2$)$. Falls from the same level occured more at home $(n=214 / 324 ; 66 \%)$, while falls from height were more common at work $(n=360$ / $451 ; 80 \%)$. Two patients were injured intentionally during a conflict.
Wednesday had the highest incidence of falls compared with other days $(19 \% ; \mathrm{n}=166)$ (Figure 2A). Twenty six percent $(n=228)$ of falls occured during the fall (September -November) (Figure 2B). Figure 3 shows the time distribution of falls by mechanism (A) and location (B) of injury. It is clear that fall from height had the highest peak at 9-11 am and occured mainly at work, while fall at the same level occured continuously during daily activity time $(8 \mathrm{am}-10 \mathrm{pm})$ at home. The estimated annual incidence of hospitalized injuries with falls in $\mathrm{Al}$ Ain city was 64.3/100,000 persons per year.

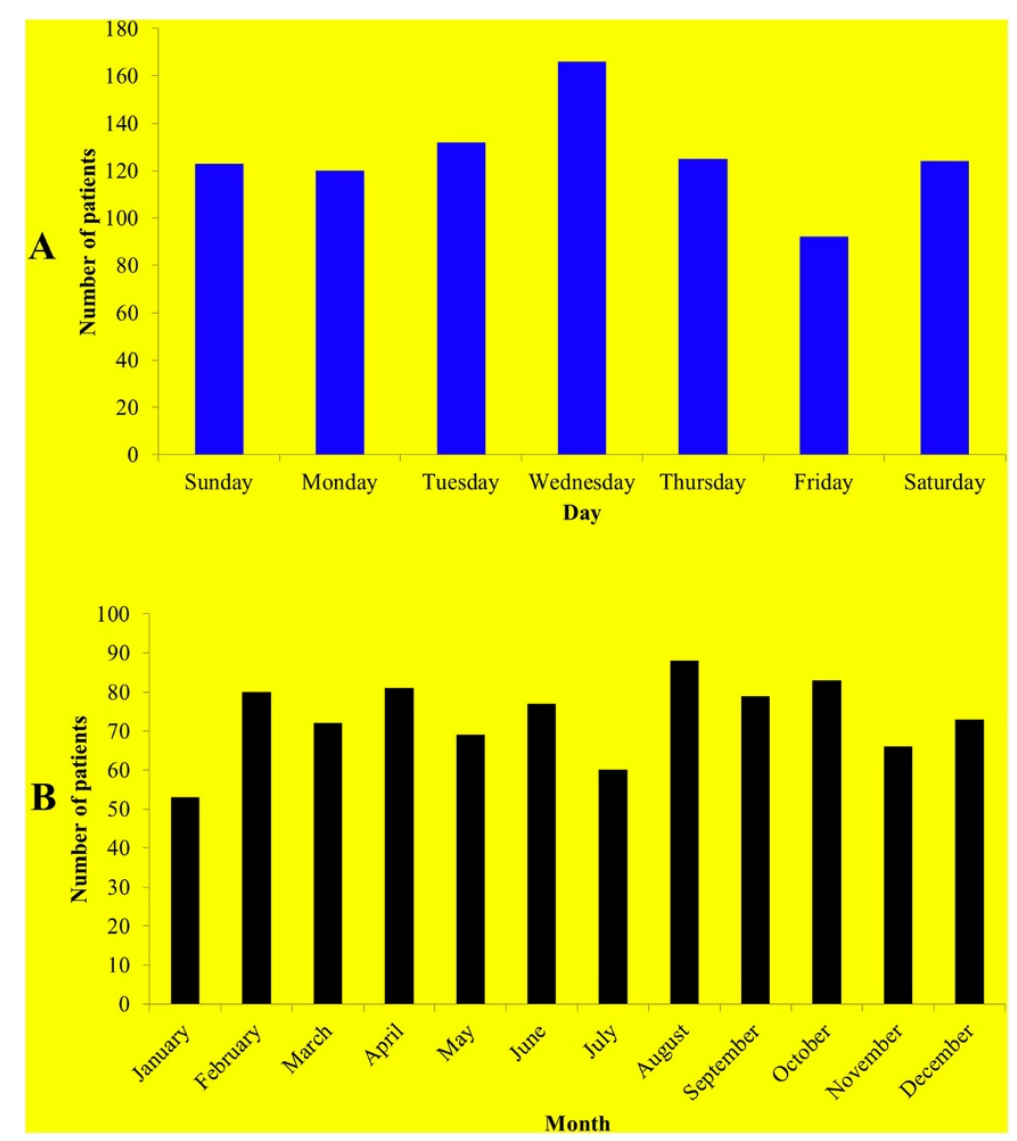

Figure 2 Distribution of fall patients by day of the week (blue bars, A) and month of the year (black bars, B). 


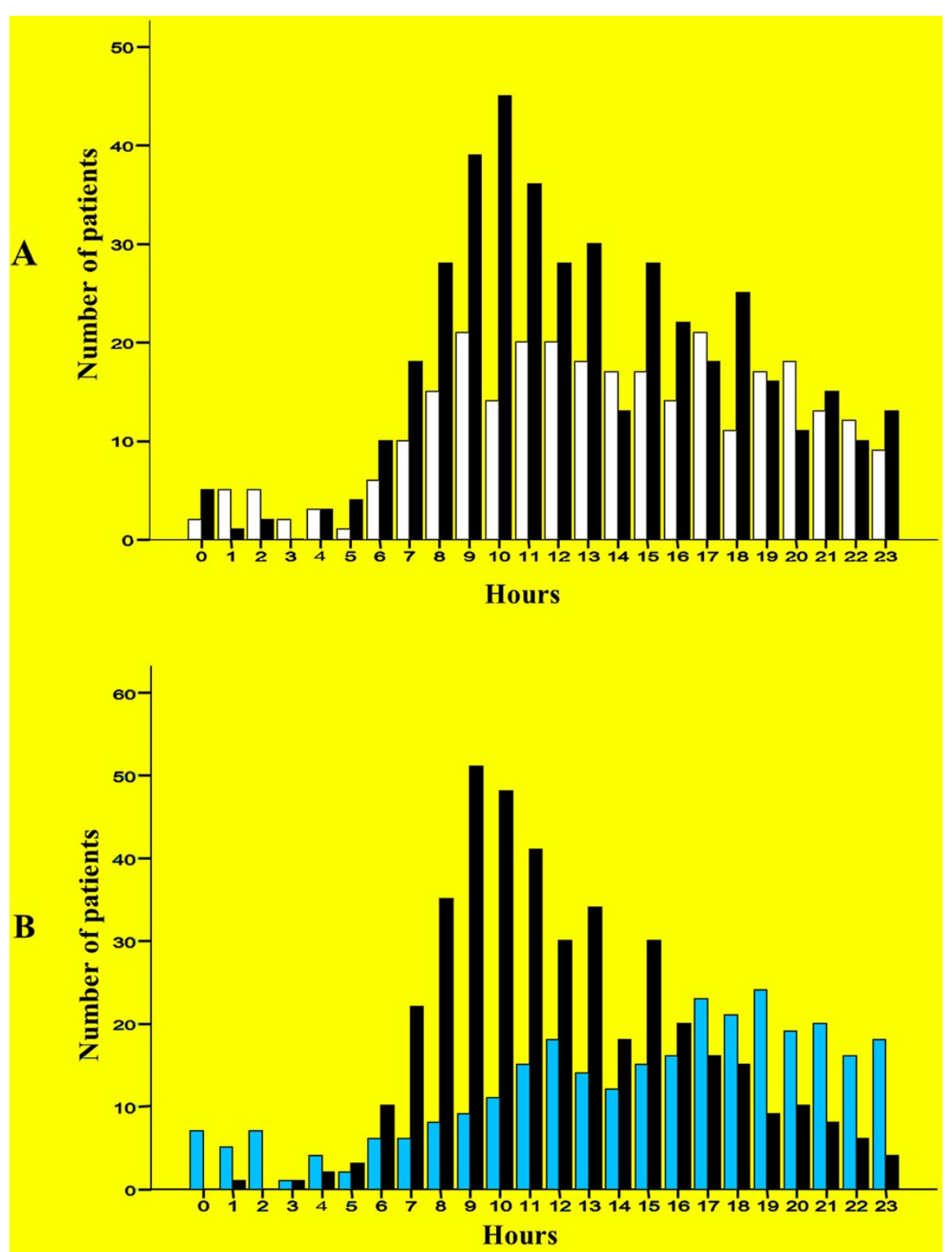

Figure 3 Time distribution of fall patients by mechanism (A) ( $n=420$ fall from height, $n=291$ fall from same level), fall from height $=$ black bars, fall from same level = white bars; and by location of trauma (B) $(n=414$ work, $n=297$ home), work = black bars, home = light blue bars.

The most common injured anatomical region was the lower extremity $(\mathrm{n}=362 / 882 ; 41 \%)$, followed by the upper extremity $(\mathrm{n}=260 / 882 ; 29 \%)$, head/face and neck $(\mathrm{n}=157 / 882 ; 18 \%)$, spine $(\mathrm{n}=115 / 882 ; 13 \%)$, chest $(\mathrm{n}=113 / 882 ; 13 \%)$ and abdomen $(\mathrm{n}=34 / 882 ; 4 \%)$. Patients who fell from height had significantly more injured chest $(\mathrm{p}<0.001)$ and spine $(\mathrm{p}<0.001)$ compared with those who fell on the same level (Table 3). There was a trend for more severe head injury for those who fell from height $(p=0.09)$. Those who fell on the same level had more severe lower limb injuries compared with those who fell from height $(\mathrm{p}<0.04)$.

The mean (SD) total hospital stay was 8.6 (11.2) days. Two patients died $(0.2 \%)$, one falling from a height and another from the same level.

\section{Discussion}

Our study has shown that the highest risk for falls for UAE nationals and females was at home, while workrelated falls were more for expatriate males. Falls from 
Table 3 Comparison of location and severity of anatomical regions between fall from the same level and fall from height of hospitalized fall-related injured patients, Al Ain Hospital, 2003-2006 ( $n=1041$ regions in 882 patients)

\begin{tabular}{|c|c|c|c|c|c|c|c|c|c|c|}
\hline \multicolumn{11}{|c|}{ Injury severity by maximum AIS } \\
\hline \multirow[b]{2}{*}{ Region } & \multirow{2}{*}{$\begin{array}{l}\text { Same level }(n=381) \\
\text { Number }(\%)\end{array}$} & \multicolumn{2}{|c|}{ From height $(n=501)$} & \multicolumn{3}{|c|}{ Same level $(n=381)$} & \multicolumn{3}{|c|}{ From height $(n=501)$} & \multirow[b]{2}{*}{ p value* } \\
\hline & & Number (\%) & p value ${ }^{*}$ & Mean & Median & $\overline{\text { Range }}$ & Mean & Median & $\overline{\text { Range }}$ & \\
\hline Head/face/neck & $63(16.5)$ & $94(18.8)$ & 0.44 & 1.51 & 1 & $1-4$ & 1.83 & 1 & $1-4$ & 0.09 \\
\hline Chest & $32(8.4)$ & $81(16.2)$ & $<0.001$ & 1.66 & 2 & $1-3$ & 1.69 & 1 & $1-4$ & 0.86 \\
\hline Abdomen & $13(3.4)$ & $21(4.2)$ & 0.68 & 1.38 & 1 & $1-3$ & 1.81 & 2 & $1-3$ & 0.11 \\
\hline Spine & $25(6.6)$ & $90(18.0)$ & $<0.001$ & 2 & 2 & $2-2$ & 2.17 & 2 & $2-5$ & 0.36 \\
\hline Upper extremity & $117(30.7)$ & $143(28.5)$ & 0.53 & 1.92 & 2 & $1-3$ & 1.85 & 2 & $1-3$ & 0.18 \\
\hline Lower extremity & 151 (39.6) & $211(42.1)$ & 0.50 & 2.26 & 2 & $1-3$ & 2.16 & 2 & $1-3$ & 0.04 \\
\hline
\end{tabular}

${ }^{*} \mathrm{p}=$ Fisher's Exact test or Mann Whitney test as appropriate; Data are presented as number (\%) or median (range) as appropriate.

the same level occured more often at home while falls from height were more common at work. Patients falling from height had more severe head injuries, were more admitted to the ICU, and had longer hospital stay when compared with those falling from the same level.

Similar to others, majority of our injured patients were males from the Indian subcontinent who were injured at work $[5,12]$. Information about occupation was missing in our study. In comparison, construction industry was regarded as the most hazardous industry in Kuwait [13]. Immigrant workers at construction sites are at high risk of injury $[5,14,15]$. They often lack safety equipment and safety education using their own language. We have previously reported the challenges faced with promoting occupational safety in the UAE $[7,16]$.

Two daily time peaks for falls were identified. They were 9-11 a.m. at work and 5-9 p.m. at home. A study from Canada reported that 11 a.m. was the peak for occupational injuries possibly due to sleep deprivation [17]. Work at the construction sites in the UAE starts earlier because of the hot climate with possible increase in tiredness and sleepiness. The mid-day break for summer months (12.30-4 pm) was introduced in 2005 so as to avoid heat-related illness. This implies that work finishes late with possible reduction in sleeping hours. Dinges et al. have shown that excessive sleepiness reduces performance and ability to stay alert, and increases the risk of errors [18]. The increased home falls at evening is possibly related to activities like dinner preparation. Falls occured more often on Wednesday which was the last working day of the week in the UAE during the study period. Thursday became the last working day of the week in the UAE on 1st September 2006 [19]. We have noticed the same time of increased injury in pedestrian and bicycle-related injuries [20,21]. The monthly incidence of falls in our study was high during August, similar to a study from Canada [17]. High outdoor temperatures, which can reach up to $50^{\circ} \mathrm{C}$, can decrease the vigilance among workers.
Fall from height occured more at work. Falling from height at construction sites was common in Qatar with significant effects on the health care system [5]. A similar study from Taiwan showed that falls were the most common cause of death at workplace [22]. A study from UK reported that slipping and tripping was the most common injury at work [23].

Falls are the leading cause of pediatric injury-related hospitalization [24,25]. Twenty two percent of patients in our study were children or youth. Families in the UAE tend to have more children who are often supervised by maids or older siblings without enough experience on first aid or safety precautions. Cases of fatal falls from higher level windows and balconies in the UAE highlighted the importance of automatic protection by passive measures, e.g. mandatory instalations of window guards [26]. A study from USA, on pediatric falls from apartment balconies and windows, found that balcony railings with more than $10 \mathrm{~cm}$ apart, and windows that were within $60 \mathrm{~cm}$ of the floor were the two most important hazards [27]. Children were previously used as camel jockeys in the UAE. They used to have major head injuries [28]. Succesful legislative intervention with substitution of child riders by robots eliminated these injuries [29].

Falls from the same level in our study occured more at home. Falls among the elderly, including same-level falls, can cause serious injuries and death [30]. Five percent of our patients were of more than 65 years old. $30 \%$ to $60 \%$ of old people fall every year and half of them have multiple falls [31,32]. Sterling et al. reported that injury severity and death for same-level falls in the elderly was twice that of the young people [30]. Home hazards for falls in the elderly include narrow steps, stairs with four or more steps, absence of railings on stairs, slippery surfaces, and insufficient lighting [33,34]. Physical environment risks are related to falls [35]. A European study showed that missing window guards at the second level or higher was a major hazard to death and disability [36]. 
The most common injured region in our study was the extremity, compared with the head in Qatar [5]. Head/face/neck in our study was the second common injured region (18\%) with more severe head injury for those falling from height. This indicates the need for safety measures, such as using helmets and installing safety barriers. The annual incidence of fall-related injuries $(64.3 / 100,000)$ in our study was lower than in Qatar $(86.7 / 100,000)$, despite that they included only occupational-related falls [5].

It is important to highlight that there are certain limitations in our study. Mortality was low $(0.2 \%)$. It is possible that patients with more severe injuries may have died before arriving to the hospital. In contrast, patients who had minor fall injuries were treated at the Emergency Department and discharged home. Furthermore, our Trauma Registry was a time-limited research project, which may not reflect the current situation and may be not generalizable to all UAE. Our study was based in $\mathrm{Al}$ Ain City, which does not have many high-rise buildings. In contrast Dubai and Abu Dhabi cities have very high buildings with more construction sites and younger labourers, so, the prevalence of falling from height may be different. Furthermore, our registry lacks data on the activity of the person during the fall, type of occupation, the detailed location of the fall at home, socio-economic variables and information on risk-taking behaviors.

\section{Conclusions}

Young males are at high risk for falls at work. Falls at work can be prevented by occupational safety education, proper legislation and regulations. Safety education in the UAE should be tailored to different ethnic groups residing and working in the UAE. Environmental modification using evidence-based architectural design can prevent home falls among vulnerable risk groups such as children and elderly.

\section{Competing interests}

All authors declare that they have no competing interests.

\section{Authors' contributions}

Conceived and designed the experiments: MG HOE FAZ. Performed the experiments: HOE. Analyzed the data: MG HOE FAZ. Contributed reagents/ materials/analysis tools: MG HOE FAZ. Wrote the paper: MG FAZ. Critically read the paper: MG HOE FAZ. Approved final version: MG HOE FAZ. All authors read and approved the final manuscript.

\section{Acknowledgements}

This study was supported by an Interdisciplinary UAE University grant (No. 02-07-8-1/4) and UAE University grant (No. NP-14-18).

\section{Author details}

${ }^{1}$ Institute of Public Health, College of Medicine and Health Sciences, UAE University, Al Ain, United Arab Emirates. ${ }^{2}$ Trauma Group, Department of Surgery, College of Medicine and Health Sciences, UAE University, PO Box 17666, Al Ain, United Arab Emirates.
Received: 22 May 2014 Accepted: 21 August 2014

Published: 2 September 2014

\section{References}

1. Runyan CW, Perkis D, Marshall SW, Johnson RM, Coyne-Beasley T, Waller AE, Black C, Baccaglini L: Unintentional injuries in the home in the United States part II: morbidity. Am J Prev Med 2005, 28:80-87.

2. Canadian Institute for Health Information: National Trauma Registry 2011 Report: Hospitalizations for Major Injury in Canada, 2008-2009 Data. Ottawa: 2011. VII. [https://secure.cihi.ca/free_products/NTR_CDS_2008_2009_ Annual_Report.pdf] Accessed August 31st 2014.

3. World Health Organization: WHO Global Report on Falls Prevention in Older Age. Geneva: World Health Organization; 2007.

4. Scuffham P, Chaplin S, Legood R: Incidence and costs of unintentional falls in older people in the United Kingdom. J Epidemiol Community Health 2003, 57:740-744.

5. Tuma MA, Acerra JR, El-Menyar A, Al-Thani H, Al-Hassani A, Recicar JF, Al Yazeedi W, Maull Kl: Epidemiology of workplace-related fall from height and cost of trauma care in Qatar. Int J Crit IIIn Inj Sci 2013, 3:3-7.

6. Liberty Mutual Research Institute for Safety: Workplace Safety Index, From Research to Reality. Hopkinton, MA: Liberty Mutual; 2012 [www.liberty mutualgroup.com/researchinstitute]

7. Grivna M, Aw TC, El-Sadig M, Loney T, Sharif AA, Thomsen J, Mauzi M, AbuZidan FM: The legal framework and initiatives for promoting safety in the United Arab Emirates. Int J Inj Contr Saf Promot 2012, 19:278-289.

8. United Arab Emirates Ministry of Health: Annual Report 2010. ; 2010:5.

9. Baker SO, O'Neill B, Haddon W Jr, Long WB: The injury severity score: a method for describing patients with multiple injuries and evaluating emergency care. J Trauma 1974, 14:187-196.

10. Maurer A, Morris JA Jr: Injury Severity Scoring. In Trauma. 5th edition. Edited by Moore E, Feliciano D, Mattox K. New York: McGraw-Hill Companies Inc; 2004:87-91.

11. Association for the Advancement of Automotive Medicine: The Abbreviated Injury Scale 1990 revision - Update 98. Barrington, IL: Association for the Advancement of Automotive Medicine; 1998.

12. Ng ZX, Teo LT, Go KT, Yeo YT, Chiu MT: Major workplace related accidents in Singapore: a major trauma centre's experience. Ann Acad Med Singapore 2010, 39:920-927.

13. Al-Humaidi HM, Tan FH: Construction safety in Kuwait. J Perform Constr Fac 2010, 24:70-77.

14. Al-Arrayed A, Hamza A: Occupational injuries in Bahrain. Occup Med 1995, 45:231-233

15. Gillen $M$, Gittleman JL: Path forward: emerging issues and challenges. J Saf Res 2010, 41:301-306

16. Grivna M, Eid HO, Abu-Zidan FM: Injuries from falling objects in the United Arab Emirates. Int J Inj Contr Saf Promot 2013. doi:10.1080/17457300.2013.863784.

17. Colantonio A, McVittie D, Lewko J, Yin J: Traumatic brain injuries in the construction industry. Brain Inj 2009, 23:873-878.

18. Dinges DF, Pack F, Williams K, Gillen KA, Powell JW, Ott GE, Aptowicz C, Pack Al: Cumulative sleepiness, mood disturbance, and psychomotor vigilance performance decrements during a week of sleep restricted to 4-5 hours per night. Sleep 1997, 20:267-277.

19. New weekend holiday to begin from September 1st. UAEinteract: 2006. [http://www.uaeinteract.com/docs/New_weekend_holiday_to_begin_ from_September_1st/21838.htm] Accessed February 9th 2014.

20. Hefny AF, Eid HO, Abu-Zidan FM: Pedestrian injuries in the United Arab Emirates. Int J Inj Contr Saf Promot 2014. Apr 10. [Epub ahead of print].

21. Hefny AF, Eid HO, Grivna M, Abu-Zidan FM: Bicycle-related injuries requiring hospitalization in the United Arab Emirates. Injury 2012, 43:1547-1550.

22. Lin YH, Chen CY, Luo JL: Gender and age distribution of occupational fatalities in Taiwan. Accd Anal Prev 2008, 40:1604-1610.

23. Health and Safety Executive: The Labour Force Survey: self-reported work-related illness and workplace injuries in 2007/08: results from the Labour Force Survey. London? Health and Safety Executive Statistics 2007, 2009:5.

24. del Río JA N, Soleto Martín J, Cerdá Berrocal J, Barrientos Fernández G, Luque Mialdea R, Estellés Vals C, de Tomás Palacios E, Vázquez Estévez J: Epidemiologic study of injuries in childhood: the first pediatric trauma registry. An Esp Pediatr 1997, 47:369-372. 
25. Al Kilani HHY, Al Mosleh AW, Khalid MK, El Tawil MS, Ibrahim TK, El Madhoun I: Pediatric trauma: a hospital based study of pattern of childhood injuries in the state of Qatar. Middle East J Emerg Med 2001, 1:1-6.

26. Emirates 24/7 News: Fatal falls from high-rises return to haunt UAE: 3 deaths in 3 days, including 2 kids; 2013 [http://www.emirates247.com/news/fatalfalls-from-high-rises-return-to-haunt-uae-3-deaths-in-3-days-including-2-kids2013-01-28-1.492704]

27. Istre GR, McCoy MA, Stowe M, Davies K, Zane D, Anderson RJ, Wiebe R: Childhood injuries due to falls from apartment balconies and windows. Inj Prev 2003, 9:349-352.

28. Nawaz A, Matta H, Hamchou M, Jacobsz A, Al Salem AH: Camel-related injuries in the pediatric age group. J Pediatr Surg 2005, 40:1248-1251.

29. Abu-Zidan FM, Hefny AF, Branicki F: Prevention of child camel jockey injuries: a success story from the United Arab Emirates. Clin I Sport Med 2012, 22:467-471.

30. Sterling DA, O'Connor JA, Bonadies J: Geriatric falls: injury severity is high and disproportionate to mechanism. J Trauma 2001, 50:116-119.

31. McClure R, Turner C, Peel N, Spinks A, Eakin E, Hughes K: Population-based interventions for the prevention of fall-related injuries in older people. Cochrane Database Syst Rev 2005, 1, CD004441.

32. Ayoung-Chee P, Mclntyre L, Ebel BE, Mack CD, McCormick W, Maier RV: Long-term outcomes of ground-level falls in the elderly. J Trauma Care Surg 2014, 76:498-503.

33. Division of Aging and Seniors, PHAC, Canada: Report on senior's fall in Canada. Ontario: Division of Aging and Seniors. Public Health Agency of Canada; 2005.

34. Marshall SW, Runyan CW, Yang J, Coyne-Beasley T, Waller AE, Johnson RM, Perkis D: Prevalence of selected risk and protective factors for falls in the home. Am J Prev Med 2005, 28:95-101.

35. McDonald EM, Girasek DC, Gielen AC: Home Injuries. In Injury Prevention for Children and Adolescents: Research, Practice and Advocacy. Edited by DeSefey Liller KD. Washington: American Public Health Association; 2006:137-140.

36. Keall MD, Ormandy D, Baker MG: Injuries associated with housing conditions in Europe: a burden of disease study based on 2004 injury data. Environ Health 2011, 10:98.

doi:10.1186/s13049-014-0051-5

Cite this article as: Grivna et al:: Epidemiology, morbidity and mortality from fall-related injuries in the United Arab Emirates. Scandinavian Journal of Trauma, Resuscitation and Emergency Medicine 2014 22:51

\section{Submit your next manuscript to BioMed Central and take full advantage of:}

- Convenient online submission

- Thorough peer review

- No space constraints or color figure charges

- Immediate publication on acceptance

- Inclusion in PubMed, CAS, Scopus and Google Scholar

- Research which is freely available for redistribution 